\title{
Durability Studies of Polyurethane-Based Structural Adhesives Used in Engineered Wood Products in New Zealand
}

\author{
Catherine L. Nicholson \\ BRANZ Ltd, 1222 Moonshine Road, RD1, Porirua, 5381, New Zealand, \\ catherine.nicholson@branz.co.nz
}

\begin{abstract}
The New Zealand Building Code is unique in the world in requiring evidence of a minimum durability of 50 years for all structural building elements. This prescriptive durability requirement equally applies to the adhesives used in structural applications such as engineered wood products (EWPS), including glulam, CLT and LVL. Conventional resorcinol-based structural adhesives have a long history of use in New Zealand, providing evidence of their ability to meet stringent durability requirements. Structural adhesives based on polyurethanes (PURs) are used extensively in other parts of the world and are rapidly gaining increasing interest in New Zealand due to their perceived environmental and production advantages. However, without a sufficiently long history of use, and a lack of data around their performance in the preservative treated pine EWPs typically manufactured in New Zealand, it is difficult to provide evidence of long-term durability for PURs in our domestic building industry. In this work, attenuated total reflectance Fourier transform infrared (ATR FTIR) spectroscopy in conjunction with multi-component analysis (chemometrics) was used to understand the changes that accelerated ageing cause in the chemistry of five PUR-based adhesives. The effect of hygrothermal stress was investigated through exposure of samples to accelerated ageing cycles of varying temperatures and humidities for up to 3 years' duration. Different samples were affected to different extents by each cycle. Spectroscopic data were also used to build predictive models which have the potential to be used in long-term durability assessment. Spectroscopic investigation in conjunction with mechanical testing offers the opportunity to provide a robust, fit-for-purpose test methodology for assessing the long-term durability of PUR-based structural adhesives.
\end{abstract}

Keywords: Adhesives, Durability, Degradation, Spectroscopy, Chemometrics.

\section{Introduction}

The inclusion of a materials durability clause within New Zealand's performance-based Building Code (NZBC) is unique in the world. This clause requires all building elements to demonstrate durability for a minimum specified time (NZ Government, 2014). In the case of structural building elements, the durability requirement is 50 years.

Structural adhesives are a critical component of engineered wood products (EWPs) including glulam, laminated veneer lumber (LVL) and cross-laminated timber (CLT). EWPs manufactured in New Zealand are predominantly produced using pine (Pinus radiata) that has been preservative treated. Chromated copper arsenate (CCA) is widely used as a timber treatment, with micronised copper azole (MCA) being a newer alternative on the market.

Traditional formaldehyde, phenolic or resorcinol-based adhesives have a long history of use in New Zealand and are known to perform well over many decades. Polyurethane (PUR) adhesives, widely used throughout Europe and North America (Lehringer et al., 2014), are attracting increasing interest from EWP manufacturers in New Zealand. However, without a 
sufficiently long history of use or long-term durability data available for its performance to be evaluated in products manufactured using preservative treated pine, it is difficult to demonstrate that structural building elements containing PUR adhesives will meet the minimum 50-year durability clause. There is, therefore, a continuing need for the development of standard test methods for the service life prediction of materials for specific applications such as these (Lee et al., 2008; Marston et al., 2011). Accelerated ageing is commonly used in these tests.

This paper describes results from a research study investigating the long-term durability of PUR-based structural adhesives. The ultimate aim of this work is to develop standard test methods which can be used for the long-term durability evaluation of products containing PUR adhesives. To achieve this, two concurrent workstreams are being undertaken. The first aims to enhance our fundamental understanding of PUR materials chemistry by subjecting adhesive films to various environmental conditions and monitoring structural changes over time. The second aims to investigate the performance of the adhesive bondline in laboratory-fabricated EWP samples through conventional mechanical testing. This dual aproach has been successfully employed by other researchers (Ren et al., 2013), who found that the complementary advantages of both methods enhanced an overall understanding of structure durability relationships in polyurethane adhesives used for timber bonding.

The focus of this paper is on the work that has been carried out on the PUR adhesive films. The effects of three accelerated weathering cycles of varying temperatures and humidities for up to 3 years' duration are reported for five commercially available PUR adhesives. The results are an extension of the preliminary work carried out on the same adhesives described by Nicholson et al. (2017) using attenuated total reflectance
FTIR) spectroscopy and chemometrics,
FTIR spectroscopy has been widely used in the analy sis of
al., 2016; Pellizzi et al., 2014; Zhang et al., 2013; Mitchell
polyurethanes (Bockel et al., 2018; Clerc, et al., 2017: Ren e

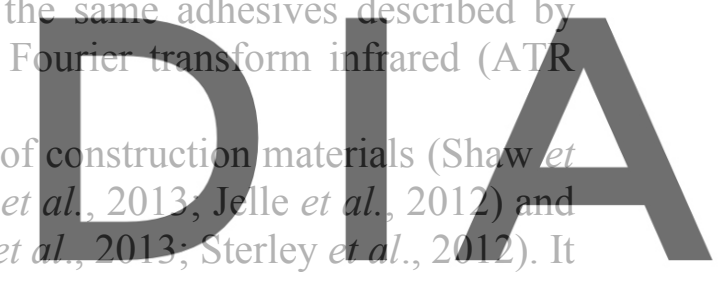

is a rapid, non-destructive analytical technique which can also be used for in situ testing.

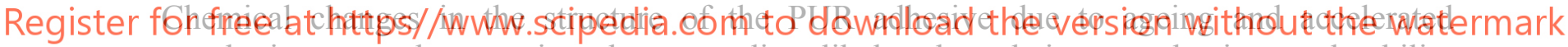
weathering can be monitored to predict likely degradation mechanisms, durability characteristics and expected service life.

The accelerated ageing cycles were chosen based on the likelihood that PURs would be subjected to hygrothermal stress under in-service conditions. It is known that under conditions of elevated temperature and moisture, the constituent polyol and urethane chemical entities may be hydrolysed (Dubelley et al., 2018). The susceptibility to and extent of degradation of individual PURs is highly dependant on composition. Photolysis induced by UV exposure is also an important factor to consider. Photolysis results are not presented here because the adhesive films used in this study were not formulated to withstand UV exposure and were severely degraded within only days or weeks of accelerated and outdoor ageing respectively.

In the preceeding work (Nicholson et al., 2017), structural changes in the adhesives exposed to accelerated ageing had been monitored over a very limited timeframe. A main conclusion was that much longer ageing times were required to build a better picture of degradation mechanisms and structural changes in order to understand the durability implications of these changes. The results reported here describe the effects of longer exposure times on the samples. The additional data now provide better insight into degradation mechanisms and have also enabled predictive models to be developed for durability evaluation. 


\section{Materials and Methods}

\subsection{PUR Adhesive Samples}

Five commercially available PUR-based adhesives were selected to undergo accelerated ageing tests. Adhesives were cast onto wooden sticks and pressed flat to minimise the effect of foaming during curing. All samples were allowed to cure for at least the minimum time recommended by the manufacturer under normal laboratory conditions (approximately $22^{\circ} \mathrm{C}, 55 \% \mathrm{RH}$ ) before undergoing testing. Control samples were stored in a constant climate laboratory at $20^{\circ} \mathrm{C}$ and $50 \% \mathrm{RH}$.

\subsection{ATR FTIR Spectroscopy and Chemometrics}

ATR FTIR spectroscopy was performed with an Agilent Technologies 4300 instrument. Snectra were collected using MicroLab PC software and a diamond ATR sampling interface over the spectral range $650-4000 \mathrm{~cm}^{-1}$. A background of 16 scans was recorded before each spectrum of 64 scans with a resolution of $4 \mathrm{~cm}^{-1}$ was acquired. Spectra were analysed and predictive models developed using GRAMS IQ (version 9.1) software. Table 1 shows the spectral regions of interest relevant to the PUR structure. Partial least squares calibration and cross-validation was used to assess the validity of the predictive models.

Table 1. Spectral band assignments for regions relevant to PUR structure in FTIR spectra (modified from
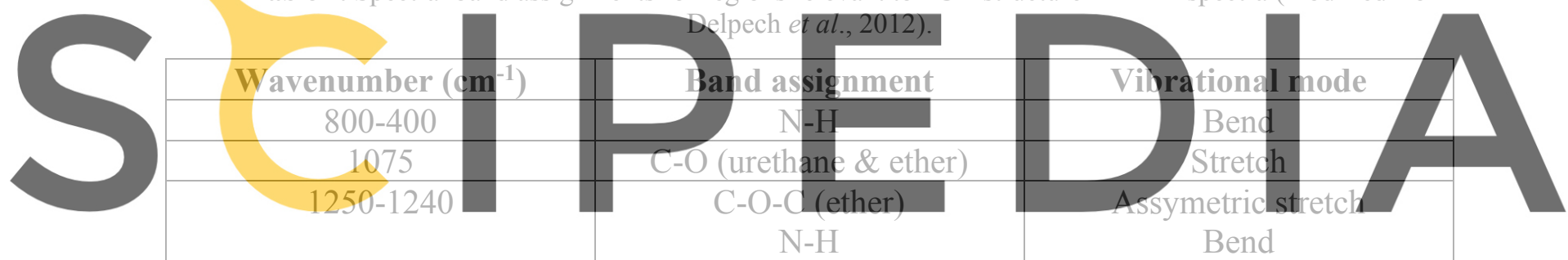

$\mathrm{N}-\mathrm{H}$

Bend

Register for free at https//www.scipedia.com t6-download the version Wittidut the watermark

\begin{tabular}{|c|c|c|}
\hline 1374 & C-H (methyl) & $\begin{array}{c}\text { Symmetrical bend } \\
\text { C-N stretch } \\
\text { N-H symmetrical bend }\end{array}$ \\
\hline $1560-1530$ & $\mathrm{C}-\mathrm{N}-\mathrm{H}$ (urea) & $\begin{array}{c}\text { C-N stretch } \\
\text { N-H symmetrical bend }\end{array}$ \\
\hline $1715-1630$ & $\mathrm{C}-\mathrm{N}-\mathrm{H}$ (urethane) & Stretch \\
\hline $2250-2275$ & $\mathrm{C}=\mathrm{O}$ (urethane \& urea) & Stretch \\
\hline $2970-2850$ & $\mathrm{O}=\mathrm{C}=\mathrm{N}$ (free isocyanate) & Stretch \\
\hline $3335-3320$ & $\mathrm{C}-\mathrm{H}$ (methyl \& methylene) & Stretch \\
\hline
\end{tabular}

\subsection{Exposure Cycles for Accelerated Ageing Tests}

The adhesive samples were exposed to a range of temperature and humidity conditions (Table 2). A complete Cycle A was 1 day in length, a complete Cycle B was 1 week in length and Cycle $\mathrm{C}$ represented constant exposure to elevated temperature and humidity. Controls were sampled at the same time intervals as the exposed samples. 
Table 2. Description of exposure cycle conditions for accelerated ageing tests.

\begin{tabular}{|l|l|l|}
\hline \multicolumn{1}{|c|}{ Cycle A } & \multicolumn{1}{|c|}{ Cycle B } & \multicolumn{1}{|c|}{ Cycle C } \\
\hline 6 hours $@ 30^{\circ} \mathrm{C}, 95 \% \mathrm{RH}$ & 5 days $@ 70^{\circ} \mathrm{C}, 90 \% \mathrm{RH}$ & Constant $65^{\circ} \mathrm{C}, 100 \% \mathrm{RH}$ \\
6 hours@ $60^{\circ} \mathrm{C}, 75 \% \mathrm{RH}$ & 1 day $@-20^{\circ} \mathrm{C}$ & \\
6 hours@ $10^{\circ} \mathrm{C}, 50 \% \mathrm{RH}$ & 1 day $@ 80^{\circ} \mathrm{C},<15 \% \mathrm{RH}$ & \\
6 hours@ $-10^{\circ} \mathrm{C}$ & & \\
\hline
\end{tabular}

\section{Results}

All five adhesives had broadly similar composition as determined by ATR FTIR (Fig. 1).

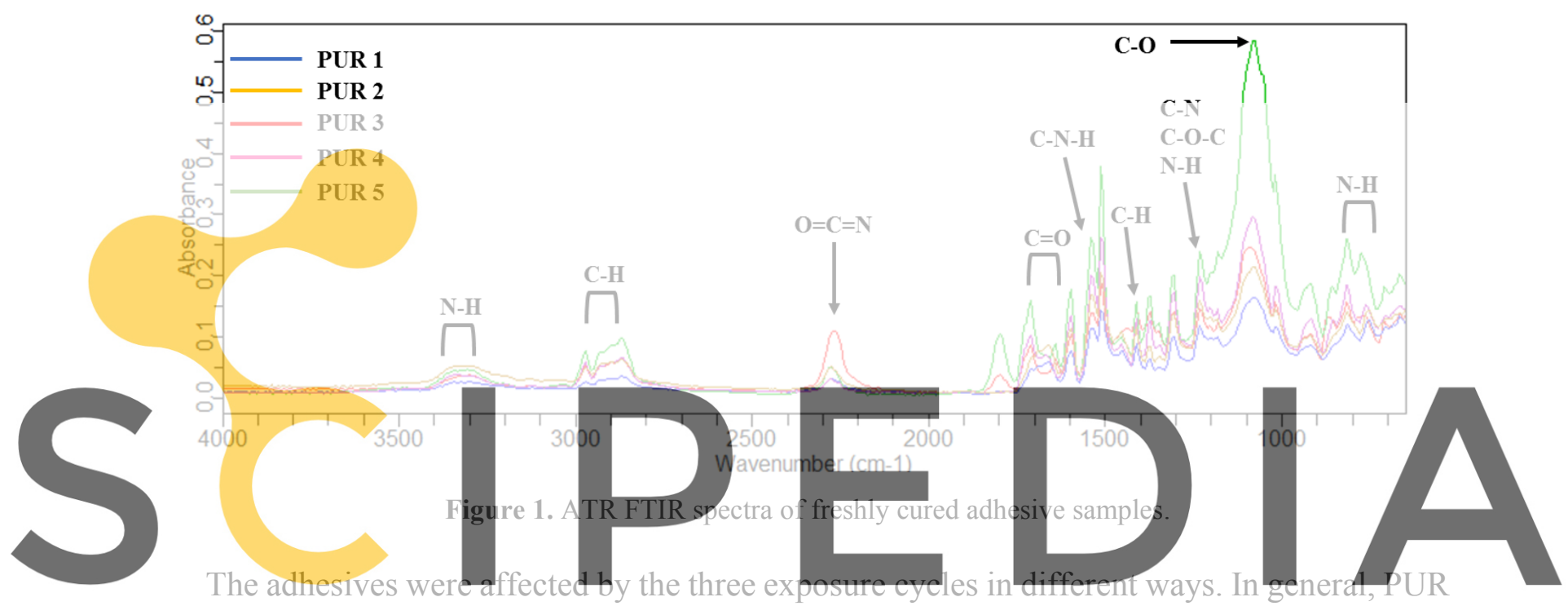

1 and PUR 2 exhibited little discernible difference between the control and aged specimens.

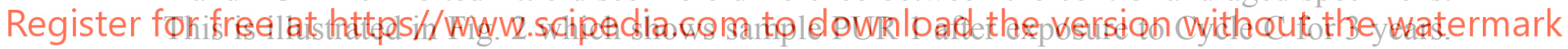

Considerable colour changes were observed for both PUR 1 and PUR 2. Originally both cream,

they turned light yellow during Cycle A, orange / brown during Cycle B and dark brown during

Cycle C. Control samples did not change colour.

Structural changes were clearly evident in the FTIR spectra of PUR 3 during Cycles B and $\mathrm{C}$ but minimal changes were apparent during Cycle A when compared with controls. These differences were observed throughout multiple regions of interest. Fig. 3 shows sample PUR 3 after exposure to Cycle $\mathrm{C}$ for 3 years. Colour changes were also observed for these specimens. Originally beige, as ageing progressed they remained beige during Cycle A, turned white and powdery during Cycle B and became chocolate brown during Cycle C. Control samples did not change colour.

PUR 4 and PUR 5 behaved in a similar manner to each other. Some differences were observed in spectra when compared with the controls during all three exposure cycles. This is illustrated in Fig. 4 which shows PUR 5 after exposure to Cycle A for 18 months. Both PUR 4 and PUR 5 darkened significantly in colour during ageing in Cycles B and C but not Cycle A. 


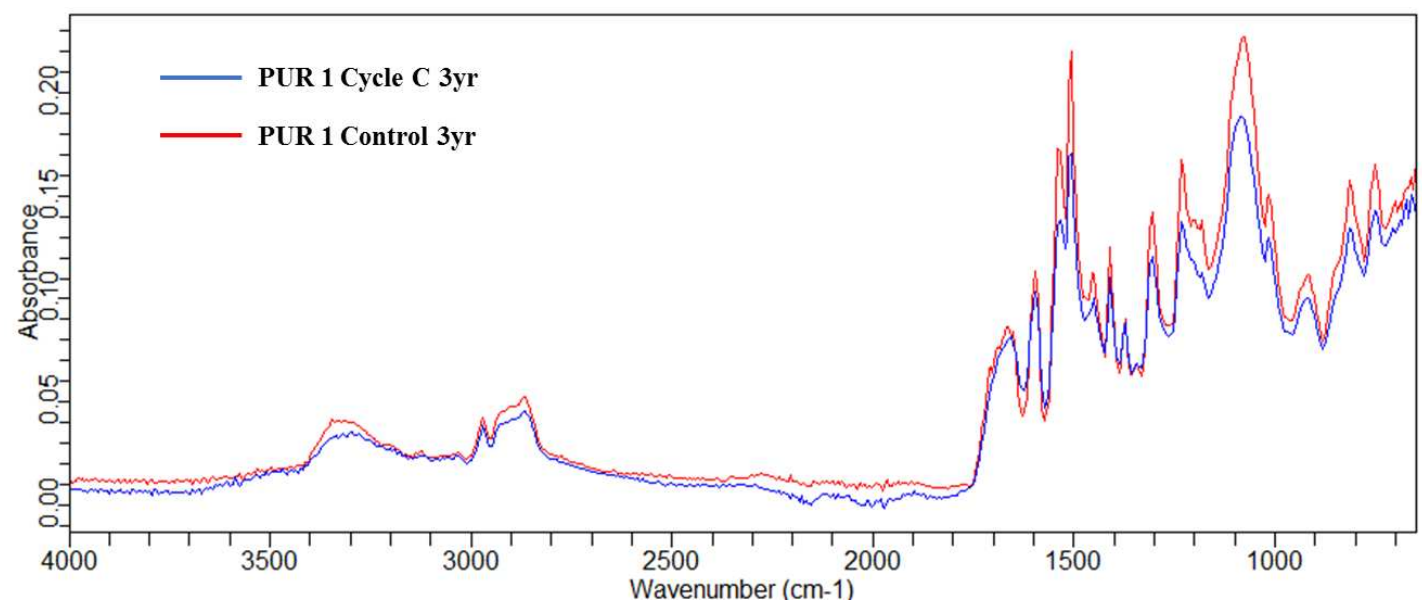

Figure 2. ATR FTIR spectra of sample PUR 1 and control after 3 years of exposure to Cycle C.

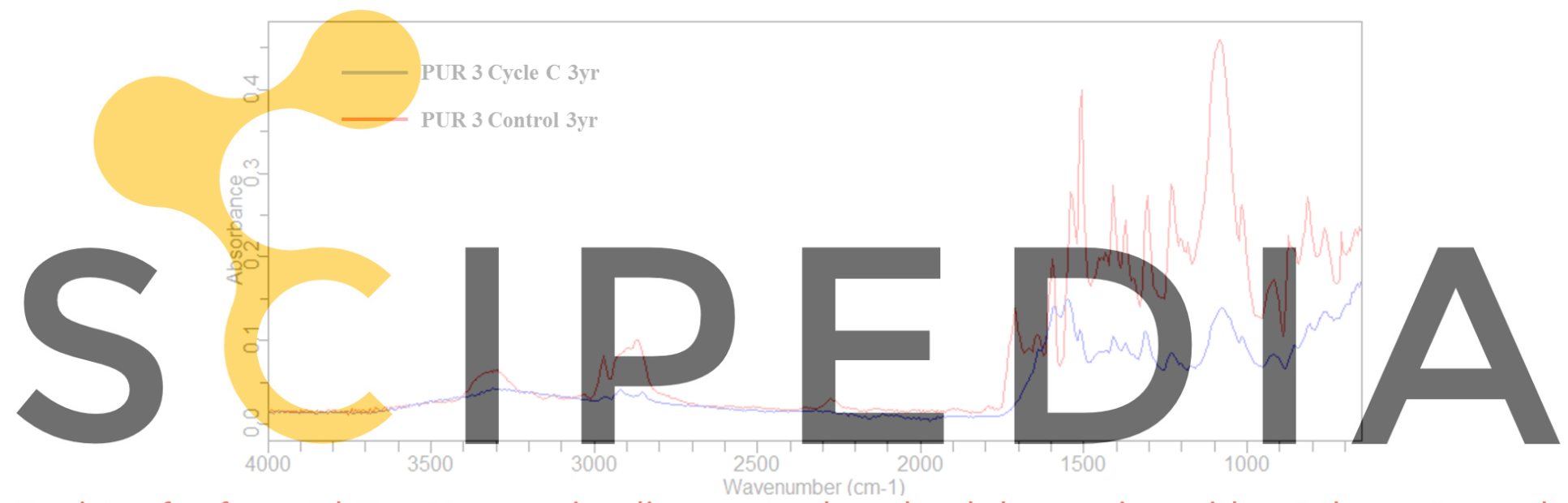

Register for free a

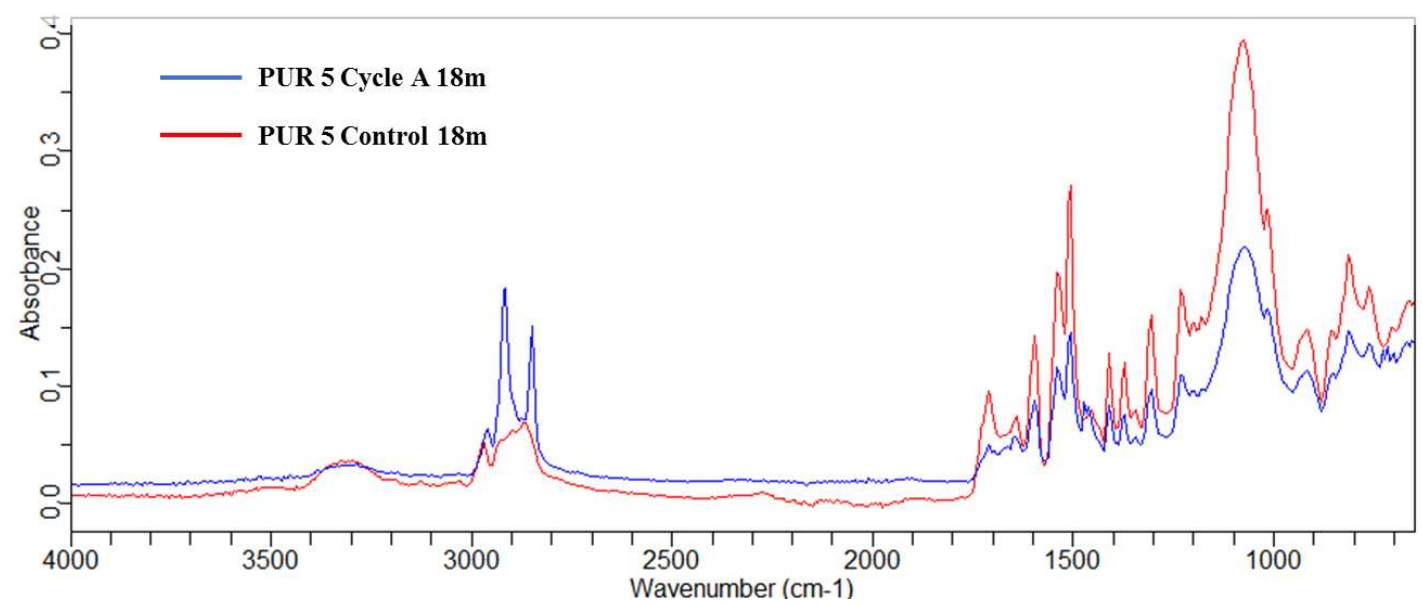

Figure 4. ATR FTIR spectra of sample PUR 5 and control after 18 months of exposure to Cycle A. 
Validation results for predictive models of each adhesive sample and accelerated ageing condition were variable. Fig. 5 shows the cross-validation plot for the predictive model using PUR 1 subjected to Cycle $\mathrm{C}$ for up to 3 years. This had a coefficient of determination $\left(\mathrm{R}^{2}\right)$ of 0.91 .

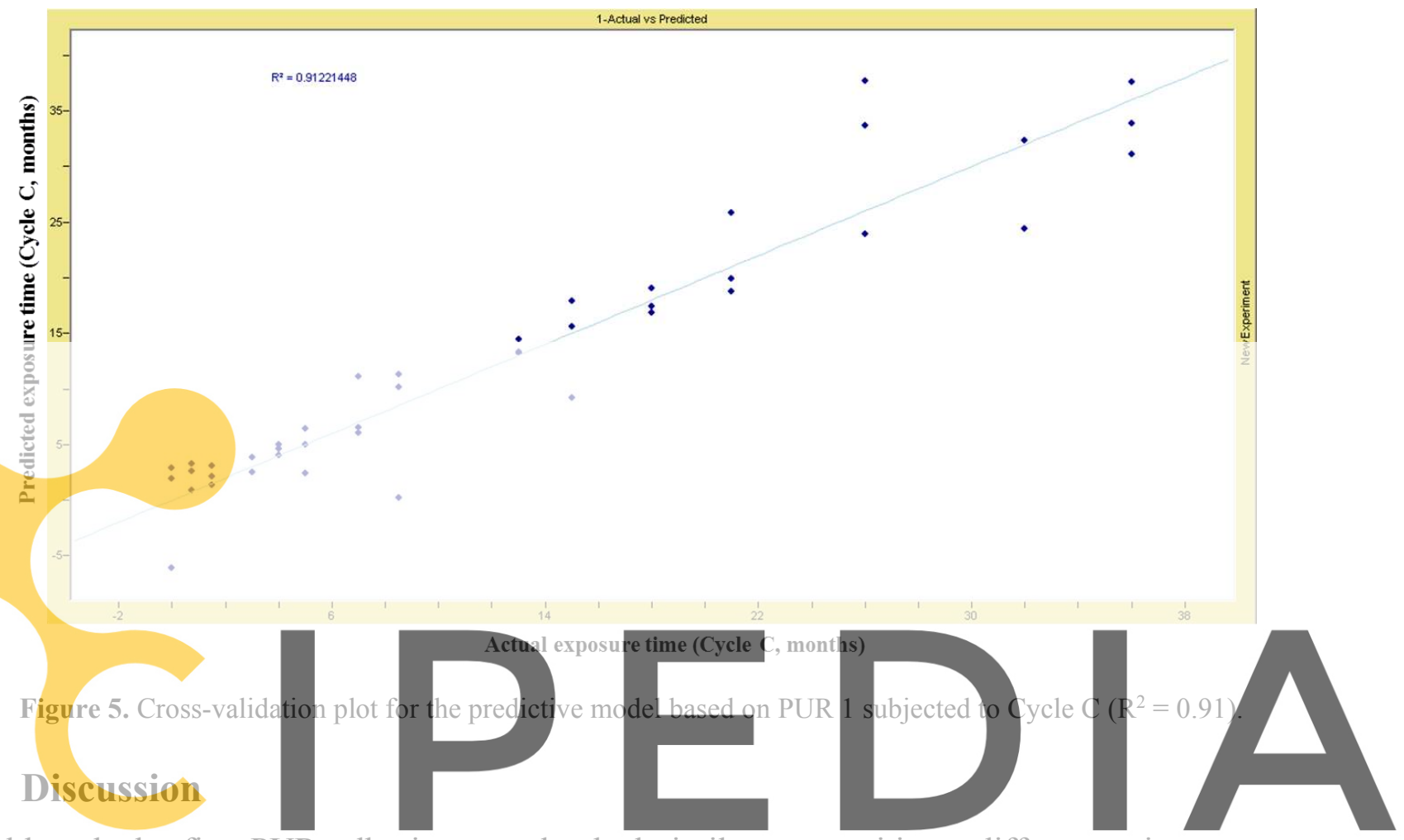

Although the five PUR adhesive samples had similar compositions, differences in spectra

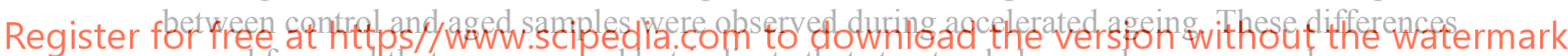
ranged from subtle to pronounced but indicate that structural changes have occurred.

PUR 1 and PUR 2 exhibited no obvious structural changes during any of the three ageing

cycles (Fig. 2). The only difference noted was the reduction in intensity and eventual disappearance of the peak at around $2275 \mathrm{~cm}^{-1}$ (Fig. 1). This is associated with free isocyanate and its disappearance would be expected as the adhesive cured. This is confirmed by the control sample which exhibited identical behaviour. On the basis of the spectroscopy data, these samples both appear to be highly resistant to hydrolysis. However, colour changes were noted, suggesting some structural changes that were not immediately apparent by spectroscopy.

In contrast, PUR 3 showed evidence of significant hydrolytic degradation during cycles B and $\mathrm{C}$ (Fig. 3). There was an overall reduction in peak intensity compared with the control, and complete loss of structure in the region $1000-650 \mathrm{~cm}^{-1}$ associated with N-H bonds and over $3400-1800 \mathrm{~cm}^{-1}$, also associated with $\mathrm{N}-\mathrm{H}$ as well as $\mathrm{C}-\mathrm{H}$ bonds (Table 1). Pronounced reduction in the peak at $1538 \mathrm{~cm}^{-1}$ asociated with $\mathrm{C}-\mathrm{N}-\mathrm{H}$ bonding is indicative of loss of the urethane structure and accounts for the observed discolouration of the samples. The disappearance of the peaks between $1750-1650 \mathrm{~cm}^{-1}$ further supports degradation of the urethane structure, being associated with the $\mathrm{C}=\mathrm{O}$ bonds in urethane. 
PUR 4 and PUR 5 showed evidence of some subtle structural changes around $1700 \mathrm{~cm}^{-1}$ associated with the $\mathrm{C}=\mathrm{O}$ and $\mathrm{C}-\mathrm{N}-\mathrm{H}$ bonds in urethane and more obvious changes between $3000-2800 \mathrm{~cm}^{-1}$ associated with $\mathrm{C}-\mathrm{H}$ bonding.

While the three exposure cycles were designed to be severe, they are not extreme relative to the New Zealand climate. Conditions experienced by building materials may well reach or even exceed $70^{\circ} \mathrm{C}$ and $80 \%$ humidity in the north of the North Island in summer and drop to $-20^{\circ} \mathrm{C}$ in the south and central South Island in winter. However, it is the continuous nature of exposure under these conditions which would not be expected in-service.

It is clear that PURs cannot be treated as a generic class of adhesives that will behave identically. The wide range of PUR adhesive formulations available, and the apparent differences in resistance to hygrothermal degradation highlighted in this work, likely precludes development of a single generic test to predict the long-term durability of a given adhesive. It is more likely that new PUR adhesives will need to be tested individually to assess performance. However, the results from this work suggest that a relatively simple accelerated ageing test based on Cycle C, i.e. performed at elevated temperature and humidity over a period of several months, would give an indication of the durability of a PUR adhesive to hygrothermal stress.

\section{The cross-validation plot for the predictive model based on PUR 1 subjected to Cycle C (Fig.} 5) suggests that it may be possible to incorporate such a model into an assessment methodology for long-term adhesive durability prediction. This model will be tested using laboratoryfabricated EWP samples which are undergoing natural outdoor ageing. This will provide a measure of the reliability of the correlation that can be expected between natural weathering
and accelerated ageing. Successful development of predictive models and conrelation of PUR
film data with mechanical testing of wood-PUR composites would assist with building a more
complete picture of long-term durability
5 Conclusions

\section{Conclusions}

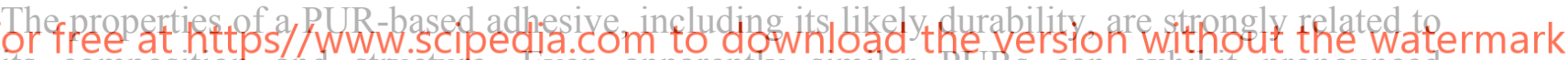 its composition and structure. Even apparently similar PURs can exhibit pronounced}

differences in behaviour when subjected to hygrothermal stress. In addition, the same adhesive did not always exhibit the same structural changes when subjected to different ageing cycles. This suggests that a generic durability test for all PUR-based structural adhesives is unlikely to be feasible.

Spectral changes indicative of structural degradation had a relatively early onset within weeks or a few months of exposure to the test cycle. A simple set up consisting of sustained high temperature and humidity could be considered as a rapid screening test for new or unknown PUR adhesives.

While spectroscopy alone cannot determine long-term durability, this technique can contribute important chemical information and complement other more conventional mechanical testing methodologies. Development of predictive models may further enhance its value. A combined spectroscopic and mechanical testing approach offers the opportunity to develop a robust, fit-for-purpose test methodology for assessing the durability and expected service life of PUR-based structural adhesives used in New Zealand-manufactured EWPs. 


\section{Acknowledgements}

This research is supported by the Building Research Levy.

\section{ORCID}

Catherine Nicholson: https://orcid.org/0000-0002-3541-5957

\section{References}

Bockel, S., Mayer, I., Konnerth, J., Niemz, P., Swaboda, C., Beyer, M., Harlimg, S., Weiland, G., Bieri, N. and Pichelin, F. (2018). Influence of wood extractives on two-component polyurethane adhesive for structural hardwood bonding. The Journal of Adhesion, 94(10), 829-845.

Clerc, G., Brulisauer, M., Affilter, S., Volkmer, T., Pichelin, F. and Niemz, P. (2017). Characterization of the ageing process of one-component polyurethane moisture curing wood adhesive. International Journal of Adhesion and Adhesives, 72, 130-138.

Delpech, M.C. and Miranda, G.G. (2012). Waterborne polyurethanes: influence of chain extender in FTIR spectra profiles. Central European Journal of Engineering, 2(2), 231-238.

Dubelley, F., Bas, C., Planes, E., Pons, E., Yrieix, B. and Flandin, L. (2018). Durability of polymer metal multilayer: focus on the adhesive chemical degradation. Frontiers in Chemistry, 6, Article 459. doi: $10.3389 /$ fchem.2018.00459.

Jelle, B.P., Nilsen, T.-N., Hovde, P.J. and Gustavsen, A. (2012). Accelerated climate ageing of building materials and their characterization by Fourier transform infrared radiation analysis, Journal of Building Physics, 36, 99112.

Lehringer, C. and Gabriel, J. (2014). Review of recent research activities on one-component PUR-adhesives for engineered wood products. In: Materials and Joints in Timber Structures, RILEM Bookseries 9, 405-420.

Lee, N.P., Bennett, J.M., Jone Zealand Building Code. and Components, Istan

Marston, N.J., Jones, M.S , a Proceedings of the XII Inter Portugal.
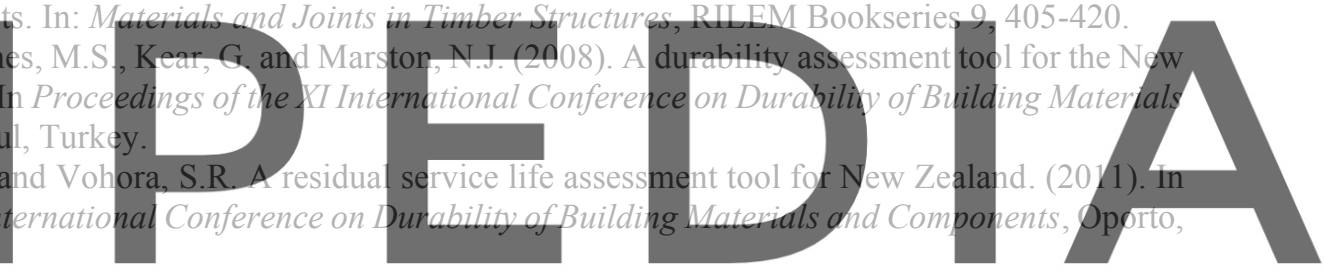

Mitchell, G., France, F., Nordon, A., Tang, P.L. and Gibson, L.T. (2013). Assessment of historical polymers using

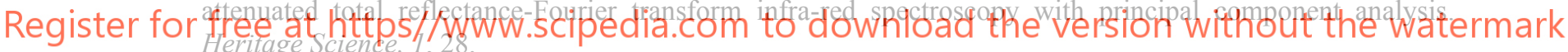

Nicholson, C.L., Shaw, P. and Marston, N. (2017). Preliminary investigation of the durability of structural adhesives using FTIR spectroscopy and chemometrics. In Proceedings of the XIV International Conference on Durability of Building Materials and Components, Ghent, Belgium.

NZ Government, Ministry of Business, Innovation and Employment. (2014). Acceptable solutions and verification methods for New Zealand Building Code Clause B2 Durability. $2^{\text {nd }}$ editition, amendment 8.

Pellizzi, E., Lattuati-Derieux, A., Lavedrine, B. and Cheradame, H. (2014). Degradation of polyurethane ester foam artifacts: chemical properties, mechanical properties and comparison between accelerated and natural degradation. Polymer Degradation and Stability, 107, 255-261.

Ren, D. and Frazier, C.E. (2013). Structure/durability relationships in polyurethane wood adhesives: neat films or wood/polyurethane composite specimens? International Journal of Adhesion and Adhesives, 45, 77-83.

Ren, D. and Frazier, C.E. (2013). Structure-property behavior of moisture-cure polyurethane wood adhesives: influence of hard segment content. International Journal of Adhesion and Adhesives, 45, 118-124.

Shaw, P. and Martson, N. Reliable durability prediction of polymeric materials. (2016). Chemistry in New Zealand, 80, 137-142.

Sterley, M., Trey, S., Lundevall, A. and Olsson, S. (2012). Influence of cure conditions on the properties of a onecomponent moisture-cured polyurethane adhesive in the context of green gluing of wood. Journal of Applied Polymer Science, 126, E296-E303.

Zhang, Y., Maxted, J., Barber, A., Lowe, C. and Smith, R. (2013). The durability of clear polyurethane coil coatings studied by FTIR peak fitting. Polymer Degradation and Stability, 98, 527-534. 